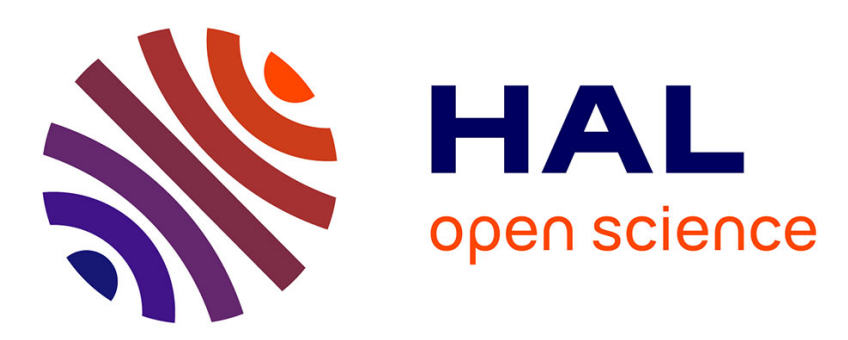

\title{
Leadership beyond the Tipping Point: toward the Discovery of Inversions and Complementary Hypotheses
}

Fabrice L. Cavarretta, Sean T Hannah, Ronald F Piccolo, Mary Uhl-Bien

\section{To cite this version:}

Fabrice L. Cavarretta, Sean T Hannah, Ronald F Piccolo, Mary Uhl-Bien. Leadership beyond the Tipping Point: toward the Discovery of Inversions and Complementary Hypotheses. 2015. hal$01214027 \mathrm{v} 2$

\section{HAL Id: hal-01214027 \\ https://essec.hal.science/hal-01214027v2}

Preprint submitted on 16 Oct 2015

HAL is a multi-disciplinary open access archive for the deposit and dissemination of scientific research documents, whether they are published or not. The documents may come from teaching and research institutions in France or abroad, or from public or private research centers.
L'archive ouverte pluridisciplinaire HAL, est destinée au dépôt et à la diffusion de documents scientifiques de niveau recherche, publiés ou non, émanant des établissements d'enseignement et de recherche français ou étrangers, des laboratoires publics ou privés. 


\title{
Leadership beyond the Tipping Point: toward the Discovery of Inversions and Complementary Hypotheses
}

\author{
RESEARCH CENTER \\ ESSEC Working Paper 1519
}

2015

Fabrice Cavarretta

Sean T. Hannah

Ronald F. Piccolo

Mary Uhl-Bien 


\title{
Leadership Beyond the Tipping Point:
}

\section{Toward the Discovery of Inversions and Complementary Hypotheses}

\author{
Fabrice L. Cavarretta \\ Management Department \\ ESSEC Business School \\ 95021 Cergy Pontoise France \\ $+133609594674$ \\ Cavarretta@essec.edu \\ Sean T. Hannah \\ Schools of Business \\ Wake Forest University \\ Winston Salem, NC 27106 \\ (336) 758-4338 \\ hannahst@wfu.edu \\ Ronald F. Piccolo \\ Crummer Graduate School of Business \\ Rollins College \\ Winter Park, Florida, U.S.A \\ +1 (402) 472-2314 \\ rpiccolo@rollins.edu \\ Mary Uhl-Bien \\ Global Leadership Institute \\ College of Business Administration \\ Department of Management \\ University of Nebraska-Lincoln \\ CBA 269. P.O Box 880491 \\ Lincoln, NE 68588-0491, USA \\ +1 (402) 472-2314 \\ muhlbien@unlnotes.unl.edu
}




\title{
LEADERSHIP BEYOND THE TIPPING POINT:
}

\section{TOWARD THE DISCOVERY OF INVERSIONS AND COMPLEMENTARY HYPOTHESES}

\begin{abstract}
Leadership theories often include a contingency effect where the relationship between two or more variables is normally theorized to be monotonic, i.e., that it has a generally accepted directionpositive or negative-across the full range of the contingency variable. Most examinations of contingencies estimate how the monotonic relationship changes at mean, or near mean, levels of the moderator variable. We push the logic of moderation further to explore whether, for extra-ordinary values of the moderator, the effect may actually become non-monotonic, e.g., invert by moving from positive to negative in slope (or vice versa). Discovering such inversion effects in models of leadership would provide a deeper understanding of the operation and boundaries of theories, thereby calling for refinements of underlying theoretical assumptions. Using an innovative inductive approach, we search the leadership literature and find studies where extra-ordinary moderator values signal a potential inversion effect. We narrow onto two example leader-member exchange (LMX) studies to inductively theorize the mechanisms creating the inversion. We then generalize the logic of this mechanism to propose new theory for why such inversions might be occurring in a wider range of phenomenon beyond LMX, and discuss the associated implications for leadership and organizational theory.
\end{abstract}

Keywords: leadership, moderation, inversion 


\section{INTRODUCTION}

Besides a limited set of constructs that assess negative leader attributes (e.g., narcissism in Judge, LePine, \& Rich, 2006) or negative leadership behaviors or effects (e.g., abusive supervision, Tepper, 2007), the overwhelming majority of modern constructs and theories of leadership seek to describe leader behaviors, competencies or attributes that have positive influence on followers, teams, and organizations in general (Bass \& Bass, 2008). We say in general because when investigating these theories, researchers tend to focus on the relationships between the mean levels of constructs in their models. We propose that this combination of a positive slant and focus on average effects has masked very important leadership phenomena and has failed to uncover crucial boundary conditions in models of leadership. We propose that leadership theories and methods too often ignore the possibility that, under certain conditions, a leadership effect thought to produce positive effects can actually invert from its theorized positive direction to instead produce negative effects (cf. Ames \& Flynn, 2007). We provide a framework to theorize such inversion effects and a methodology to explore their empirical plausibility.

Theories such as Fiedler's (1970) contingency theory, House's (1996) path-goal theory, and Hersey and Blanchard's (1969) situational leadership theory have long held that leadership effectiveness is contingent on factors such as task, context and follower attributes, with leader behaviors being most effective when they "match" what is called for by the various contingencies. Many frameworks of leadership have grown out of these earlier contingency theories, continuing to attempt to determine the conditions or "matches" under which various forms of leadership are most effective, on average. Such frameworks, however, have rarely considered important variability effects

that may lead to the inversions noted above. These theories prescribe which forms of leadership may best match a certain set of situational parameters, but not how various levels of that form of leadership influence outcomes across the construct's full range. 
Thus, leadership theory typically considers that higher levels of positive leadership are better, but can there be too much of a 'good' thing. Can, for example, extreme high levels of transformational leadership cross a boundary condition where the leader is perceived as being too visionary and inspirational and thus aloof and not grounded in the realities of their organization? This suggests that these constructs have inverse effects on outcomes in their extreme ranges as opposed to the rest of the construct's range. The possibility of such inversions can offer important new discoveries concerning the operation and theorizing of leadership.

Variability effects associated with inversions occur in moderated relationships where the predictor, theorized to be positively related to the outcome across the full range of the moderator (i.e., a monotonic relationship), actually becomes negatively related to the outcome in part of the moderator's range (i.e., non-monotonic relationship as described in Schoonhoven, 1981). This creates an inversion point, which we define as the critical point of the moderator construct where the relationship between predictor and outcome switches from positive to negative. We assess the potential that some moderated relationships between leadership constructs are non-monotonic beyond certain critical values of the moderators. We focus on moderators as they-by their nature-establish contingencies or boundary conditions for leadership theories, which we propose are all the more important if they can create an inversion of the predictor-outcome relationship.

Thus if non-monotonic, the generally agreed direction of a contingent relationship is only valid for certain levels of the moderator. For example, Dysvik and Kuvaas (2008) found that when leaders offer training opportunities to followers, the training raised followers' organizational citizenship behavior (OCB) on average, with that main effect moderated by intrinsic motivation such that the relationship between training opportunities and $\mathrm{OCB}$ was more positive at higher levels of intrinsic motivation. By reconsidering the possibility of a non-monotonic effect in this study, however, as we will report below, it is possible that at very low levels of intrinsic motivation (roughly at or below 2.8 
on a 5 point scale) the relationship between training opportunities and OCB is not just lower, but inverts and becomes negative; something not considered in that study. This might occur, for example, if followers with extremely low levels of intrinsic motivation are complacent and withdrawn and seek to exert minimal levels of effort at work, and thus see training opportunities as a burden or as infringing on their personal time.

Identifying such inversion points in moderator constructs would not replace the traditional focus of hypothesizing the effects between mean levels of constructs but, rather, complement existing theories and lead to new discoveries. Specifically, researchers could theorize and test not just meaneffect hypotheses but also complementary bypotheses, which we define as secondary hypotheses that predict the "theoretical space" of the non-monotonic relationship, reflecting the inversion occurring around the critical value of the moderator - the boundary condition.

We discuss in the following section that relationships may be non-monotonic due to shifts in individuals' perceptions of a focal construct (the predictor) across different levels of the contingency concept (the range of the moderator). For scale scores near an inversion point that exists in the lower range of an organizational justice scale, for example, an individual may be expressing a low level of perceived justice. Scores even lower, below the inversion point, however, might instead indicate perceived injustice, thereby evoking a different psychological phenomenon that inverts the normally observed positive relationship between justice and workplace outcomes. The possibility of inversions thus not only has empirical implications, but more importantly, significant implications for how we conceptualize, build and test theory, and inform practice.

Inversion effects naturally occur away from the mean of a moderating factor and thus are somewhat extra-ordinary (e.g., in the Dysvik and Kuvaas (2008) example above, our analysis suggests it would occur in $6 \%$ of the cases). Yet, it is possible that some of the most interesting and important examples of successful and unsuccessful leadership occur under somewhat extraordinary 
contingencies characterized as being less probable yet highly impactful (Taleb, 2007). Examples of such cases include large changes in profitability, performance, or firm survival or large shifts in organizational systems (Baum \& McKelvey, 2006; Denrell, 2003) or in situations where contexts are highly extreme or volatile (Hannah et al., 2009).

A deeper understanding of inversions occurring in leadership phenomenon can not only help refine theories, but also help to determine why and under what conditions leadership interventions (e.g., inspirational motivation or individualized consideration) may fail, or fail for some particular followers, groups, or contexts. Such understanding can also highlight what contingent factors need to be addressed or corrected in order for future interventions to be successful.

We proceed using an inductive versus deductive logic. Our motivation to assess inversion effects leads to an empirical exploration of a sample of previously published empirical studies, the results of which feed an inductive theoretical elaboration to explain a basis for the potential inversions discovered in our analyses of those studies. Our pursuit represents first a theoretical contribution to the conceptualization of non-monotonic relationships in leadership theories. We also aim at a secondary yet important methodological extension of previous treatments of contingencies in literatures besides leadership (e.g., Aiken, West, \& Reno, 1991; Schoonhoven, 1981). We demonstrate a new exploratory approach to suspect inversion effects ex-ante that is highly flexible and allows the estimation of inversions without requiring access to primary data, but rather through the modeling of the underlying effects of the moderator on the variability of the outcome variable using data commonly reported in published studies.

We conduct an empirical exploration on a convenience sample of 29 leadership studies in which an inversion was not already being reported (e.g., all regression lines in the moderation graph have either a positive slope or a negative slope) and for which all necessary information needed to calculate the inversion point is available. Our innovative approach allows us to straightforwardly 
determine five studies for which an inversion might be potentially occurring. To explore the theoretical basis for such findings, we conducted vignette inductive theoretical elaboration on those studies, and then focused and report on two studies to articulate a deeper inductive theoretical elaboration. This led us to theorize how extremely low levels of Leader-Member Exchange (LMX) may invert the relationship between transformational leadership and followers' perceptions of their work (core job characteristics, a reinterpretation of Piccolo \& Colquitt, 2006), and between procedural justice and felt obligation (a reinterpretation of Piccolo et al., 2008). We chose to focus on these studies as exemplars because leadership is an inherently relational construct and followers often view and interpret leader behaviors through the perspective of relationships (Uhl-Bien, 2006). Therefore, we believe that the components of LMX (such as trust, liking, and respect) have a high potential to be non-monotonic. Specifically, as suggested by Sparrowe and Liden (1997), negative forms of exchange may occur at lower levels of LMX, and not reflect concepts such as trust, liking, and respect; but distrust, disliking, and disrespect (Uhl-Bien \& Maslyn, 2003). We draw from implicit leadership theory (ILT, Lord \& Maher, 1993) and affect infusion (Forgas, 1995, 2001) to explain these inversions. We propose that when leaders match followers' prototypes of a poor leader (i.e., an antiprototype, Epitropaki \& Martin, 2004) that the associated negative affect they experience will infuse their processing of the leaders' influence attempts to the extent that the effects of otherwise 'positive' leadership behaviors have negative impacts on those followers. We develop complementary hypotheses to represent this theorizing, extending the boundaries of LMX theory. We conclude by applying these findings beyond LMX to identify select mechanisms that might underlie inversions operating more broadly in other leadership and organizational theories.

\section{THE BASIS AND IMPORTANCE OF SEARCHING FOR INVERSIONS}

We propose that by linking the effects of moderators to increases in the variability in outcome constructs, researchers can identify where effects on variability could be signaling that the 
relationships might turn non-monotonic. For example, consider the LMX perspective, which frames leadership phenomena according to the quality of the relationship between the leader and each follower (Graen \& Uhl-Bien, 1995; Sparrowe \& Liden, 1997). Piccolo and Colquitt (2006) studied the effect of transformational leadership on followers' perceptions of their job characteristics, and considered LMX as a potential moderator of this relationship. Following classical approaches, they found a positive moderation (reproduced in Table 2.a). This result is based on mean and near mean (+/- 1SD) levels of LMX, and focuses on how the generally agreed upon positive effect of transformational leadership on followers' perceptions of job characteristics somewhat varies depending on values of the LMX moderator.

However, the dampening of the effect of transformational leadership when LMX goes down signals that there may be a potentially interesting theoretical phenomenon operating in the extremely low range of LMX. Empirically, this could be interpreted as an increasing dispersion of the outcomes when the moderator LMX moves away from its mean toward the lower range of the scale (e.g., a fan-like pattern of job characteristics exemplified in Table 2.a). Yet, from a theoretical standpoint, transformational leadership and LMX are classically considered positive leadership constructs, and thus consideration is not given to the possibility that the effect of transformational leadership might be qualitatively altered to the point of inversion, creating negative effects on job characteristics below a critical threshold of LMX.

Despite this, there is some recognition in the literature that social exchange relationships as reflected in LMX can range not only from higher quality to lower quality, but also degrade to negative forms of exchange where parties seek to take more than they give or to damage the other party (cf. Sparrowe \& Liden, 1997; Uhl-Bien \& Maslyn, 2003; Zahn \& Wolf, 1981). Whereas traditional measures of LMX assume that high and low scale scores represent levels of the concept that exist on a simple monotonic continuum, a more nuanced appreciation of the concept 
recognizes that very low scores on an LMX scale may potentially indicate negative relationship attributes, such as disrespect versus low respect. Similarly, in the trust literature, Schoorman, Mayer and Davis (2007) argue that trust and distrust are not on the same continuum. Such theorizing infers that followers can psychologically re-conceptualize these constructs differently across the continuum of their full range.

We noted that the vast majority of leadership constructs and theories are positively oriented, and typically use measures which do not allow participants to rate leadership or leadership relationships as negative, only as more or less positive (e.g., as more or less visionary, transformational, or of higher or lower quality LMX). Even scales using "disagree" as an anchor evidence the absence of a phenomenon (e.g., trust), not necessarily the presence of another phenomenon (e.g., distrust). When rating a leader who they distrust, for example, a follower may interpret the lower range of the scale differently than a follower who has low levels of trust (but not distrust) for his or her leader. For instance, we will inductively theorize in a later section specific psychological phenomena occurring at low levels of LMX that might create such re-conceptualizations and inversions.

Thus, the possibility of non-monotonic relationships and their resulting inversion effects has significant implications for theory building. Yet studying such possibilities requires the ability to explore whether inversions may be happening within a certain range of factors. We offer a new methodological approach to explore such intuitions so that more atypical yet-interesting leadership phenomena can be discovered. We begin by considering that inversions are likely to occur through effects on variability (Denrell, 2003; Kalnins, 2007) produced by the effect of a moderator on the variance of the outcome (Keppel \& Wickens, 2004:208). Because we focus on substantive theory, our logics concerning variability and our methodology for estimating critical values at which an inversion may be occurring are briefly explicated, in Appendix A. 
A moderator operates to create variance in the relationship between a predictor and an outcome construct (i.e., a main effect). Moderated relationships can become non-monotonic beyond a certain value of the moderator at which the variance effect it implies makes the main relationship invert. Such an inversion was identified in a study from the macro organizational literature on structural contingency theory by Schoonhoven (1981), in which she challenged the predominant idea that contingent factors (environmental uncertainty and organizational structures) have a monotonic-i.e., always beneficial or always detrimental—effect on organizational efficiency. Rather, she suggested that qualitative changes could occur beyond a certain threshold value of the moderator, at a level that can be determined analytically (1981:377). This possibility has also been studied in the statistical literature on the interpretation of ordinal vs. disordinal interactions (e.g. , Aiken et al., 1991). We apply a similar approach, using a new methodology, to the micro organizational phenomena of leadership research.

For the rest of this paper, the change in a slope (i.e., a slope line as seen in a common moderation graph such as Figure 1) occurring when a relationship turns non-monotonic will be referred to as an inversion. It will always refer to a change in the sign of the influence between variables specified in a normative theory: something normatively thought to be detrimental becomes beneficial, or beneficial becomes detrimental. ${ }^{1}$

------ Insert Figure 1 here -----

We proceed in two steps. First, we conduct an empirical exploration to demonstrate an efficient method for detecting potential inversions. We use this method on a sample of existing studies to identify cases in which unreported, inversion phenomena are potentially occurring. From these ${ }^{1}$ Inversion should not be confounded with an idea of change in the direction of causation. Inversion is just a change in the direction to which the main factor increases or decreases the dependent variable. 
results we choosing one of these phenomena, inversions in the low end of LMX, and engage in inductive theorizing and propose new theory for why such inversions might be occurring.

\section{EMPIRICAL EXPLORATION}

We conduct an exploratory discovery process to examine reported results of moderation in the leadership literature, to assess whether, and at what critical threshold, an inversion might occur in a sample of existing studies. Because of the exploratory nature of our research, we conduct an inductive, rather than deductive, empirical inquiry. We thus present our methods and results prior to our theoretical induction. Further, our goal was to achieve a representative sample of quality studies to exemplify variability effects, not to assess the total population of leadership studies.

Our sampling of existing studies might appear similar to that used in meta-analysis, yet is fundamentally different. The goal of a meta-analysis is most often deductive (to verify the direction of an effect). It uses a statistical technique that allows for testing inference, i.e., allowing statistical estimation. By contrast, the current study is inductive. We explore primary studies to discover signals of interesting and undocumented extra-ordinary leadership phenomena. Our statistical tools are not intended to construct an estimation but rather to detect a sample of interesting cases, out of which we_or others_ could later inductively build and test substantive new theory.

Other ways of directly testing for inversions exist which require access to primary data and samples large enough to contain significant numbers of data points located beyond the inversion point in order to provide adequate statistical power to confirm the inversion (e.g., Aiken et al., 1991; Schoonhoven, 1981). By contrast, one would use the method employed in this study if trying to explore various phenomena searching efficiently for inversion effects using data commonly reported in published papers. 


\section{Analytic Procedures}

The analytic procedures were developed following the method proposed by Schoonhoven to compute the level at which an inversion might occur (1981:377 appendix A), but with some significant technical and conceptual differences. Schoonhoven studied the possibility of inversions by testing it on a specific phenomenon (i.e., structural contingency theory) and using primary data from an existing hospital patient database (1981). We take an alternative path given our interest in the inductive discovery of effects occurring across a sample of phenomena that can be applied across a breadth of studies. Schoonhoven's calculation formula cannot generally be used when only secondary information (as reported in studies) is available, as it requires access to primary data and hence is inappropriate for an exploratory approach. Technically, Schoonhoven's method could be used if the coefficients of the moderated regressions are available, but this information is not universally provided in published studies. For instance, studies may report the result of the moderation not in a table but in the text, providing only change in percentage of variance explained (e.g., Piccolo \& Colquitt, 2006:334). Alternatively, studies using hierarchical linear modeling (HLM) may only report "slopes-as-outcomes" (e.g., Erdogan, Liden, \& Kraimer, 2006). Because of the lack of comprehensive and specific information about the interaction (e.g., regression cross-factor coefficients), current analysis techniques prevent researchers from broadly surveying studies to detect potential inversions and thereby guide new theory building.

By contrast, the typical moderation graph is nearly universally available, with readable and exploitable metric information. Furthermore, the existence of the graph is necessary to determine, visually and quickly, the basic characteristics of the moderation (main slope, ordinal or not, crossing or not, etc.), which may be ambiguous if relying only on a regression table. We therefore developed a new method that allows estimating the level at which an inversion might occur by exclusively relying on the information commonly available in moderation graphs. The exact steps and the 
technical details of our method are described in Appendix B. We conducted checks on studies for which coefficients were provided, and verified that both our and Schoonhoven's (1981) methods reached similar conclusions.

\section{Base Sample Selection}

We began by searching for a representative set of leadership studies in a select set of top tier management journals (e.g., Academy of Management Journal, Strategic Management Journal, Organizational Science, Administrative Science Quarterly, and Journal of Management) as well as select psychology journals (e.g., Journal of Personality and Social Psychology, Personnel Psychology, and Journal of Applied Psychology), published between 2000 and 2009, by searching the Business Source Complete/EBSCO database on the keywords "leadership" and "moderation," "moderating," "interaction" or "interacting."

We selected studies that reported a moderation effect and contained an exploitable graph (of the style illustrated in Figure 1.a), and for which the other required information listed in Appendix B was available. For instance, some studies were eliminated because they did not report the mean of the moderator (therefore preventing the computation of the critical value of the moderator $M_{c}$ ) or did not report the exact scale for the moderator variable, preventing us from assessing whether the values where inversions may occur would be within the scale range.

Among the papers with appropriate information, we omitted studies where the graph or text already acknowledged the existence of an inversion, e.g., the graph has one positive slope and one negative slope, or it surfaces from the text that the non-monotonicity is already established. We retained those where only one direction of the effect (either positive or negative) was considered, and therefore, the possibility of inversion was not considered. This process led to the identification 
of a sample of 29 studies for which the possibility of inversion can be calculated and where an inversion would constitute theoretical novelty. They constitute our base sample of studies. ${ }^{2}$

\section{Results}

Our computations, using the formulas from Appendix B, identified that in five of the 29 studies the main effect appears to change slope beyond a critical threshold value of the moderator. The five studies constitute roughly $1 / 6$ of the exploitable studies, a ratio consistent with the idea that inversions in the extremes may be suspected to occur relatively frequently, yet not systematically. In Table 1, we provide basic information about these studies, and in Table 2, we reproduce the figures from each of the studies that we used in our analyses.

\section{------ Insert Table 1 and Table 2 here -----}

We conducted vignette theory building, which provided the basis for our inductive theorizing, for all five studies. Due to space limitations, however, this theorizing is only reflected in the "potential mechanism" column of Table 1 and we only focus on more elaborative theorizing for two of these studies: Piccolo and Colquitt (2006) and Piccolo et al. (2008).

We chose these two studies for inductive theorizing for two reasons. First, the common moderator (LMX) across these two studies cued that some more general theoretical phenomenon may be at work. Second, as suggested above, low levels of LMX constitute a natural area to consider the possibility of inversions, and thus the need for complementary hypotheses (i.e., proposing countervailing effects to those predicted by the primary hypotheses in these studies).

The results for those two studies follow. In Piccolo and Colquitt (2006), we find that at low levels of LMX (at or below 1.9 on a 5-point scale) the relationship between transformational

${ }^{2}$ This process does not generate any sample selection biasing issue since the objective is to find a basis to conduct an inductive exploration, not to conduct formal statistical analysis on the amount of studies that could be liable to such inversion. 
leadership (TFL) and followers' subjective job perceptions (i.e., job characteristics) appears to invert to become negative. This finding calls for further investigation because, in general, the relationship between TFL and job perceptions is conventionally thought to be positive, with the positive relationship even more enhanced when relationship quality is high (Table 2.a shows the original graph that was considered from that study). In Piccolo et al. (2008), we find that, at low values of LMX (at or below 2.73 on a 5-point scale) ${ }^{3}$, the effects of procedural and interpersonal justice on an employee's sense of obligation to the organization appear to invert to become negative. Again, this finding calls for further investigation because the relationship between justice and sense of obligation is conventionally considered to be positive, with this relationship further enhanced when followers experience high quality LMX relationships with their leaders (Table 2.a shows the original graph that was considered from that study).

\section{THEORETICAL INDUCTION: INVERTED EFFECTS AT LOW LMX LEVELS}

In this section, we theorize the basis for the inversions occurring at low levels of LMX. To do this we draw from research on followers' implicit leadership theories (ILT, Lord \& Maher, 1993) that trigger affect infusion (Forgas, 1995, 2001). We first review key literature in those areas.

\section{Anti-Prototypical Leaders and Negative LMX}

Leadership research has increasingly recognized that leadership is largely in the eye of the beholder. Leadership is, at its core, a positive influence process, and for leadership to occur, the target the leader seeks to influence (e.g., follower or peer) has to first be open or receptive to the leader's influence attempts (Bass \& Bass, 2008; Yukl, 2010). The extent that a follower is receptive to a leader's influence is based in large part on the follower's expectations, perceptions, attributions and

\footnotetext{
${ }^{3}$ In the same study (Piccolo et al., 2008), we also suspected an inversion for interpersonal justice. That is not reported further here because of the great theoretical and empirical similarity.
} 
other factors driven by cognitive prototypes (Epitropaki \& Martin, 2004; Foti \& Lord, 1987; Lord, Foti, \& De Vader, 1984). According to implicit leadership theory (ILT, Lord \& Maher, 1993), followers will perceive the same leader differently based on their idiosyncratic prototypes of what constitutes an ideal leader and the extent to which they judge the leader to match that prototype. As a form of cognitive categorization theory (Rosch, 1978), ILTs are developed through prior experiences with actual leaders, the study of leaders or leadership, or other sources of experience that individuals encode into memory as the traits, knowledge, skills, and abilities associated with an ideal leader (Kenney, Blascovich, \& Shaver, 1996; Lord et al., 1984).

ILTs have previously been applied to LMX theory (Engle \& Lord, 1997; Epitropaki \& Martin, 2005). Lord and Mayer (1993) argue that perceptions of LMX are mediated through ILTs, such that followers interpret the dimensions underlying LMX (e.g., whether they trust, respect, or like the leader) through the lens of their ILT and assess the extent to which the individual matches their prototype. The literature on LMX, like most contemporary theories of leadership, however, is positively oriented in that it theorizes and commonly assesses the extent to which varying levels of LMX positively influence outcomes directly or in interaction with other variables.

More recent research on ILTs, however, suggests that followers not only encode into memory a leader prototype but also a leader anti-prototype, representing their prototype of negative leader qualities (e.g., manipulative, selfish, conceited, etc.) as a separate cognitive categorization (Epitropaki \& Martin, 2004). What would occur then—when a follower's assessment of a leader does not simply reflect the absence of trust, respect, or liking as specified in LMX, but dislike, distrust and disrespect because the leader matches the follower's anti-prototype? We suggest that such a situation will create a boundary condition on LMX, where conceptual shift occurs at a certain lower range of the LMX construct, a shift from LMX to "negative-LMX" (cf. Uhl-Bien \& Maslyn, 2003). Such a conceptual shift, which is consistent with our analysis, might invoke non-monotonic phenomena with 
inversions occurring at low levels of LMX. Research by Epitropaki and Martin (2005) has indeed demonstrated that when there is a difference between followers' ILT prototypes and their perceptions of their leader, that difference is negatively related to levels of LMX. Further, research has found that the direct relationship between LMX and outcomes such as stress and turnover intentions is curvilinear, with increased negative effects on these outcomes occurring at extremely low levels of LMX (e.g., Harris \& Kacmar, 2006). Research has not assessed, however, how extremely low levels of LMX relate to other constructs in a model in which LMX is moderating the relationship between two other constructs as we do here.

Further, LMX relationship quality manifests in forms of exchanges used. Research has generally proposed that lower levels of LMX are reflected in more transactional and economic exchanges based on quid pro quo, while higher levels of LMX are reflected in social exchanges that extend beyond mere employment contracts and offer emotional and social support (Graen \& Uhl-Bien, 1995; Schriesheim, Castro, \& Cogliser, 1999). Aligned with our thinking, in theorizing the processes and structure of LMX, Sparrowe and Liden (1997) encouraged researchers to consider not only economic and social exchange relationships but also the potential that negative forms of exchange may be operating where parties seek to take more than they give (cf. Zahn \& Wolf, 1981). Those could create negative social dynamics that could lead to the inversions we observed. Therefore, we suggest that by not theorizing or allowing enough range within constructs to capture non-monotonic relationships generated at or past inversion points, we may be missing an important dimension of LMX.

\section{Negative-LMX and Affect Infusion}

While the mismatch of leaders to followers' prototypes can explain the existence of negative LMX, it does not explain why extremely low LMX, in turn, may negate or invert the effects of (otherwise positive) leadership. A potential theoretical explanation for why LMX, as a moderator, 
can create inversions in the relationships between two other constructs (i.e., the relationship between transformational leadership and core job characteristics) is affect-infusion (Forgas, 1995, 2001). The Affect Infusion Model (AIM) is an information processing theory that describes how positive and negative affective states or moods influence the processing of social information. Researchers have increasingly recognized that thought and behavior are inextricably connected to how people in organizations feel (e.g., George, 1990; George \& Jones, 1997; Zajonc, 2000), with affect influencing both what people think and how they think (Forgas, 2001). The AIM proposes that affect "infuses" information processing and thus shapes the formation of attitudes, values, and judgments (Forgas, 2001). Negative affect infusion is likely when interacting with an anti-prototypical leader and in reaction to the negative forms of exchanges that occur between such parties. Researchers (e.g., Srull \& Wyer, 1989) propose that affect is stored in cognitive schemas, such as ILTs, and is then activated along with those schemas when primed. Further, we know from research on negativity bias (Ajzen, 2001) that negative information tends to have greater impact on perceptions and evaluations than positive information. The priming of affect associated with ILTs and the negativity bias suggests that followers would be more likely to infuse negative affectivity into information processing when exposed to anti-prototypical leaders, thereby influencing perceptions of leadership. This occurs as "activation of an emotional node also spreads activation throughout the memory structures to which it is connected" (Bower, 1981:135). This spreading activation would thus influence information processing related to perceptions, attitudes, and other constructions influencing the follower's reactions to the leader.

Consider one follower who, when considering his or her level of trust in a leader (a dimension of LMX) thinks, "I trust him a little, but only so much." This interpretation would likely be influenced by neutral or low levels of positive affect. Another follower, however, may rate their leader lower on LMX, below the critical threshold, and thinks, "Trust? Give me a break...not as far as I could throw 
him." Each of these two followers would likely interpret the lower range of the trust factor of LMX differently-the latter as negative LMX. When this occurs, we would expect that extremely low levels of LMX would trigger negative affect and deleteriously affect the relationship between leadership constructs and outcomes. There is some indirect evidence of this proposed relationship between LMX at low levels and negative affect. Harris \& Kacmar (2006) found that LMX has a curvilinear relationship with stress, with LMX at low levels being particularly related to high levels of stress. We suggest this is what may be occurring in the inversions identified by our analysis of Piccolo and Colquitt (2006) and Piccolo et al. (2008).

\section{Applying to LMX Studies under Investigation}

Piccolo and Colquitt (2006). In our investigation of Piccolo and Colquitt (2006), we find that at low levels of LMX, the relationship between transformational leadership and followers' subjective job perceptions (i.e., job characteristics) appears to invert and become negative. Normally this would be surprising, as transformational leadership has been one of the most studied leadership constructs over the last three decades and has shown positive effects over a breadth of follower outcomes (Bass \& Bass, 2008; Dumdum, Lowe, \& Avolio, 2002; Gardner et al., 2010; Hiller et al., 2011; Lowe \& Galen Kroeck, 1996). Consistent with our theorizing of a "complementary hypothesis," however, we propose that when LMX is extremely low, the relationship between leader and follower might be characterized by distrust, disrespect, dislike, and disloyalty. In such cases, a leader's attempt to utilize behaviors consistent with a transformational pattern may not only fail to inspire positive judgments about work (i.e., the effect of transformational leadership on job characteristics is zero), but actually cause a negative judgment of work by followers. That is, at extremely low levels of LMX, in which the follower regards the leader negatively (e.g., as selfish, biased, and untrustworthy), attempts on the part of the leader to inspire the follower by using charismatic appeals, telling vivid and eloquent stories, or using other transformational behaviors might be perceived by the follower as 
manipulative, insincere, or even sinister. Bass and Steidlmeier (1999) and others (e.g., Avolio \& Gibbons, 1988) theorized that transformational leaders can be classified as either authentic or inauthentic "pseudo-transformational" leaders, distinguishing those leaders using transformational behaviors for pro-social purposes and who genuinely want to develop and inspire followers from the inauthentic pseudo-transformational leaders who use transformational behaviors for self-serving reasons. This would be reflected in conditions of very low or negative LMX.

For a follower engaged in a relationship with an anti-prototypical leader thus triggering extremely low or negative-LMX, we would expect negative affect infusion to influence the manner in which the follower processes and interprets the leader's behaviors. For example, if the leader uses individualized consideration behaviors, such as attempting to counsel the follower about his or her personal work goals, the follower may interpret the leader's behavior as simply "checking the box" in order to look good to his/her own supervisor, or the follower may even interpret the leader's behavior as manipulative. Importantly, organizations and what constitutes work are considered to be social constructions (Harquail \& Wilcox King, 2010) whereby leaders provide a 'lens' through which followers make sense of an organization (Gerstner \& Day, 1997; Weick, 1995). Individuals are therefore particularly sensitive to how they are treated by superiors, and low LMX may promote an individual's psychological isolation from an organization. Consistent with our findings, it is plausible that these feelings on the part of the follower reveal themselves in negative interpretations about the nature of one's work and the organization, as measured by subjective job perceptions (i.e., job characteristics) and organizational culture.

Piccolo et al. (2008). In Piccolo et al. (2008), our analysis suggests that the relationship between leaders' enactments of fair procedures (i.e., procedural justice perceptions) and followers' felt obligation to the organization inverts to become negative at low levels of LMX. Drawing on similar logic concerning Piccolo and Colquitt (2006) above, when a follower experiences an extremely low 
quality relationship with an anti-prototypical leader, attempts by the leader to enact justice behaviors may be seen as manipulative or insincere. To explore such a possibility, one has to consider the potential phenomena influencing the justice-obligation relationship when LMX relationships are particularly poor. Measures of procedural justice, including the one used by Piccolo et al. (2008), tend to capture fairness as evident by expressed and public policies governing organizational decisions. For followers with extremely low, or negative LMX, negative affect infusion may influence the way they interpret those public demonstrations and the attributions made concerning leaders' intentions (e.g., as lacking sincerity or as mere "window dressing" that does not reflect those leaders' true beliefs or intentions). In turn, this leads to negative effects of justice at low levels of LMX on followers' felt obligation to the organization.

Overall, our empirical analysis and theoretical induction leads us to suggest propositions that could be formulated into complementary hypotheses and empirically tested in future research. These representative propositions are of the type that can be formulated based on expected inversions to reflect new boundary conditions in many other areas of leadership research:

Proposition 1: At extremely low levels of LMX, transformational leadership will have a negative relationship with core job characteristics perceptions.

Proposition 2: At extremely low levels of LMX, procedural justice will have a negative relationship with felt obligation.

\section{DISCUSSION}

\section{Theoretical and Practical Implications for LMX research}

Our results suggest that, in the lower range of LMX, the relationships between certain leadership constructs that are normally thought to be positive (e.g., the relationship between transformational leadership and core job characteristics perceptions; and between procedural justice and felt obligation) invert to become negative. These results suggest that LMX is non-monotonic when 
operating as a moderator. We inductively theorized this is due to the effects of follower antiprototypes on LMX and resulting negative affect-infusion. If differing phenomena are operating across the full range of the LMX construct, this would create increased variability in outcome variables, which leads to inversion effects beyond a certain threshold (e.g., the inversion occurring between 1.56 and 2.73 on a 5-point LMX scale in the two focal studies). Given that relationship quality is central to leadership influence processes and serves as a 'lens' that leadership is interpreted through (Graen \& Uhl-Bien, 1995; Uhl-Bien, 2006), we further suggest that it is possible that LMX has non-monotonic relationships with other 'positive' leader behaviors beyond transformational and justice behaviors and their various outcomes.

If researchers are aware that LMX has the potential to trigger inversions, our results suggest those studying LMX as a contingency can theorize and test complementary hypotheses to account for inversions in an a priori manner. Further, researchers expecting potential inversions can add variables to their models to account for the inversion. For example, we theorized in part that extremely low levels of LMX would cause followers to assess their leader's behaviors as manipulative or self-serving, leading to negative affect infusion. Researchers could directly measure such attributions, helping to explain the cause of the inversion. Defining the boundary conditions for LMX theory and identifying countervailing phenomena occurring beyond those boundaries can thus make important contributions to refining theory.

An understanding of inversions related to LMX could also lead to important advances in measurement. For example, building on Uhl-Bien and Maslyn (2003), we suggest that the inversions occurring at extremely low LMX levels indicate that the range of LMX likely extends beyond low LMX (i.e., low levels of trust, respect or loyalty) to negative LMX, characterized by distrust, disrespect and disloyalty. Like most leadership measures, LMX measures do not allow participants to rate LMX as negative, only as more or less positive. Even scales using "disagree" as an anchor evidence the 
absence of a phenomenon (e.g., trust), not the presence of another phenomenon (e.g., distrust). Thus, respondents are likely conceptually altering the meaning of the construct at extremely low levels, interpreting the scale differently (i.e., as negative leadership). LMX, like trust (Lewicki \& Wiethoff, 2000), may be a construct that ranges beyond low and high to extreme low (negative) or extreme high (Harris \& Kacmar, 2006), suggesting that new measures or measurement techniques are necessary to represent the full span of the construct.

Practically, understanding how the low range of LMX operates could help organizations understand why interventions intended to produce positive effects may instead produce negative effects. For example, based on our analysis of Piccolo and Colquitt (2006), providing transformational leadership behavioral training to work unit leaders may have negative effects on those followers who have low LMX relationships with those trained leaders. Our results also suggest the importance of leaders and followers establishing a minimum level of relationship quality, or organizations may need to consider reassigning leaders or followers to break any "toxic" dyads (Lipman-Blumen, 2005). Given the wide range of phenomena involving LMX, this substantive boundary could prove crucial.

\section{Theoretical Implications for Leadership Research in General}

The findings across the five studies listed in Table 1 demonstrate that when researchers focus their theorizing and methods on leadership effects at or near the mean, they may fail to capture the non-monotonic nature and thus the full complexity of the relationships occurring in constructs operating in leader-follower relations. This neglects some of the dynamism occurring in the modern workplace, and the robustness of interactions that occur based on extremely high and low levels of leadership moderator constructs. Our limited sampling suggests an order of magnitude of one in six published studies for which theory could be extended by recognizing complementary hypotheses that address potential inversions. 
More in-depth exploration of inversions - by our approach or any other variation from existing literature (e.g., Aiken et al., 1991) - could help improve the accuracy and ecological validity of leadership theories. In the case of Piccolo et al. (2008) described above, if suspecting that a share of the sample reacted negatively to the leader's attempts to employ procedural justice, researchers can begin to inquire why such countervailing effects occur and design new studies to test those explanatory mechanisms. Empirical testing would require including enough cases with very low LMX, the logic of which we clarify practically here.

The approach we propose is designed to leverage and interpret reported results of existing studies that might not have considered more extreme ranges, hence allowing a more broad based exploration than other methodologies. Once focused on a specific question, however, given that data points past the inversion point are limited compared to the rest of the sample, it is important in the design of any study of inversion effects collecting primary data to ensure, ex-ante, adequate statistical power exists to allow the estimation of the inversion point.

Our results overall suggest that researchers should take caution in assuming that any leadership construct is entirely 'positive' or 'desirable.' Important boundary conditions may exist for constructs thought to have positive effects on outcomes (e.g., transformational leadership, justice, work unit identification, and training opportunities in the five studies abstracted in Table 1) based on contingencies that have also been widely accepted as positive constructs (i.e., LMX, team orientation, means efficacy, and intrinsic motivation in those five studies). Given the relational nature of leadership, and leaders' effects on establishing justice, equity, etc., the generalized model linking leader prototype schemas to valenced affects (e.g., positive vs. negative affect) provides a starting basis for the systematic identification of boundary conditions of extant theories to help explain countervailing theoretical effects (Glynn \& Raffaelli, 2010). 
Acknowledging variability effects is particularly critical for the field of leadership as researchers begin to investigate more extreme leadership contexts, such as volatile and high performance business contexts or extreme contexts such as military, police, fire, or disaster responses where unusual contingencies can amplify volatility in outcomes beyond what is normally expected (Hannah et al., 2009). Even in everyday managerial contexts, despite extreme outcomes being rare, their impact is disproportional since organizational actors are particularly sensitive to events in the extremes (Hu, Blettner, \& Bettis, 2011), and even more so for negative extremes (Baumeister et al., 2001).

\section{Theoretical Implications Across and Beyond Leadership Research}

Future examinations of inversions could address other central concepts of organizational studies, such as in micro phenomena, the study of individual differences like personality. Advances in testing models of personality, such as the "Big Five" trait taxonomy (Costa, 1992) have provided evidence for the stable and significant effects of individual traits on both positive (e.g., job performance in Barrick \& Mount, 1991; leadership in Judge et al., 2002) and negative behaviors (e.g., counterproductive work behavior in Salgado, 2002). However, personality scores that are in the extreme ends of their respective scales may capture constructs that are inconsistent with the scale's mean, producing countervailing effects on observed behavior. Extremely high levels of conscientiousness or diligence, for example, could reflect "dark side" personality traits such as subclinical levels of obsessive-compulsive disorder which have been shown to influence leader derailment (Hogan, Hogan, \& Kaiser, 2010). Thus, the relationship between personality and behavior may be non-monotonic.

Further, ILT schemas are in no way unique to LMX but are thought to mediate followers' perceptions and interpretations of a wide range of leadership behaviors and phenomenon (Epitropaki \& Martin, 2004; Foti \& Lord, 1987; Lord et al., 1984). Therefore, we suggest that when a 
leader matches followers' anti-prototypes it may alter their perceptions related to other contingency constructs, and thus create inversions. For example, consider a model where perceived leader integrity is used as a moderator of the relationship between inspirational leadership and follower performance. When a follower is exposed to an anti-prototypical leader who is believed to be selfserving and conniving, the follower may assess the construct of perceived leader integrity as nonmonotonic such that the lower range of the construct is not considered to be low integrity, but to be negative-integrity (i.e., unethical). According to the AIM model, ensuing negative affect infusion could influence perceptions of the leader's attempts to be inspirational, and prompt the follower to interpret these behaviors as manipulative or inauthentic, resulting in an inversion of the otherwise positive relationship between inspirational leadership and follower performance.

We thus believe the AIM framework (Forgas, 2001) is particularly useful for explaining some inversions. Affect is ubiquitous in the everyday social interactions in the workplace and influences a host of outcomes (e.g., Brief \& Weiss, 2002; Staw, Sutton, \& Pelled, 1994). Negative affect infusion shifts the way followers process information and could thus explain why constructs that are positively related in part of their parameter range are negatively related in other parts of their range. Indeed, such effects of valenced affect arise in other literatures, most notably the prospect theory of decision science (Kahneman \& Tversky, 1979), which associates radically different information processing when individuals are primed on losses vs. gains.

\section{Methodological Implications}

Contingency theories have been a staple of leadership research since the earliest formal leadership studies (Bass \& Bass, 2008; Yukl, 2010). While the importance of moderation effects for leadership theorizing is indisputable, we have proposed that the dynamic and complex nature of leadership contingencies may be underestimated, in particular in extreme ranges of constructs. Foremost, our results and subsequent theoretical inductions across five studies suggest that 
variations within constructs may reveal changes in the nature of the construct on the one hand, and that those intra-construct variations may have important effects on the relationships between constructs on the other hand.

It is important to reinforce that we are not refuting the analytic techniques or findings presented in the primary studies we analyzed. Instead, they were selected because they were all high quality studies published in top journals using commonly accepted methods. Yet, as discussed earlier regarding Figure 1, a theory about average outcomes can be normatively counter to a theory about what occurs in the more extreme range of constructs that may produce extra-ordinary outcomesand researchers can defend the results of each approach as legitimate. Our intended contribution is to provide researchers with the motivation and ability to analyze and report both phenomena, through including both primary and complementary hypotheses.

The current study provides the template to enhance any studies for which moderation is detected, both for new studies or to revisit existing studies. It provides an exploratory method to detect inverted effects when the moderators reach a critical value. Our sampling of literature suggests that of the 29 studies where an inversion was not already obvious, one out of six showed an inversion to be occurring within the stated range of the moderator. This ratio of possible inversions suggests that future primary research studies may incorporate such checks to investigate potential inversion effects. The choice of method will depend on the information available. Our simple technique was developed to provide results even with the most basic information presented in commonly reported graphs of interaction effects.

Finally, the current study provides an important perspective on the contentious issue of outliers (Daft \& Lewin, 1990). Our logic introduces reasons why data points otherwise thought to be "outliers" might instead have central relevance to the phenomenon under investigation. This is due to moderators increasing the spread of outcomes to the extent that select data points fall out of the 
expected pattern. These data points are then not anomalies to be discarded, but potentially meaningful findings that are counter to the primary hypothesis under investigation, and should instead be retained and be formally recognized through theorizing a complementary hypothesis. We provide a way to conceptualize then compute whether the outliers are systematically related to a particular value of the moderator that falls beyond the critical value, thus being caused by an ensuing variability effect.

\section{Practical Implications}

Identifying the counter-theoretical effects of leadership can also inform the practice of leadership. Researchers often frame constructs such as transformational leadership or LMX as positive in any and all quantities. Interestingly, across the contingencies in the five studies we assessed, our analyses showed that factors that are traditionally thought to be beneficial (e.g., transformational leadership) can actually have detrimental effects on outcomes (i.e., team orientation and leader effectiveness) at extra-ordinary levels of a contingency variable. These findings imply a need to reassess assumptions of the practical effects of leadership when moderators are operating.

Let us consider a substantive example of the practical utility of this proposed approach for organizational interventions. Our analysis of Walumbwa et al. (2008) suggests that followers' identification with the organization may reduce, versus increase, performance if their means efficacy (i.e., confidence that tools and others in one's context are of high quality and can thus be used to increase performance) is extremely low. Armed with this information, leaders can design interventions to first target the development of means efficacy in followers, or at least those followers with low levels of means efficacy, as suggested by Eden and Sulimani (2002) prior to implementing efforts to increase organizational identification.

Within the studies we analyzed, the percentage of each sample potentially affected by the inversion effects range up to $17 \%$ and thus cannot be dismissed as negligible as they may have 
important effects on workplace phenomenon. The importance of these practical effects, even on a small subsample, is increased when investigating critical outcomes such as workplace health, safety, harassment or assault, or performance of core organizational functions-all factors with possible negative disproportionate consequences (e.g., Baumeister et al., 2001). Further, parsimonious assessments of which outcomes are most likely to occur-such as how leaders affect firm performance on average-leave many rare yet critical practical phenomenon untested, such as large swings in profitability, performance, or firm survival (Baum \& McKelvey, 2006; Denrell, 2003). These rare extreme outcomes can have the greatest impact on things like an organization's policy and survival (Starbuck, 2009; Taleb, 2007). Successful firms may thus use the logic we propose to develop ways to induce 'positive anomalies.'

In particular, this approach is relevant to leadership in more volatile and extreme contexts. The samples in the current study were conducted in relatively benign work contexts, yet more particular complex contexts have started to be considered in our scholarship (Marion \& Uhl-Bien, 2007). More extreme contexts such as military, firefighting, law enforcement or hospital emergency rooms can create particularly unique conditions that influence leadership phenomena in ways that increase the observed range of leadership constructs (Hannah et al., 2009). Followers' perceptions of their leader's competence, for example, may be more varied when lives or careers are on the line and each follower estimates how their leader's competence may affect their personal safety or welfare. This greater spread in followers' perceptions may place more followers in the subsample beyond the 'tipping point' where inversion effects are occurring. This suggests that in highly complex or extreme contexts complementary hypotheses proposing inversion effects may be critical to properly model leadership. 


\section{Future Research and Conclusion}

The theories we proposed to explain the inversions occurring in our focal studies were deductively derived and should thus be considered tentative until further tested. Our purpose was not to test new theory, but to highlight the need for new theory development concerning complementary hypotheses related to inversions, and promote testing of those theories in future research to refine models of leadership.

Our analyses allowed estimating the point where inversion effects could occur, but did not allow post-hoc testing of hypotheses. Tests for inversions using the primary data in the relatively smallsample studies used in our analyses would not have allowed sufficient power to verify our predictions, since it is unlikely that in such relatively small samples that sufficient data points would fall into the extreme range where inversion is expected to occur. The current approach provides the logic and motivation to conduct similar explorations and future research that could either reanalyze existing studies that contain enough data points in the range of the inversion (e.g., Schoonhoven's (1981) use of a large archival database), combine samples such as used in meta analyses, or design empirical explorations specifically targeting that range for which various methods for the direct testing of inversions exist (e.g., Preacher, Curran, \& Bauer, 2006). Further, researchers could conduct interviews or use other qualitative methods to explore those countervailing phenomena.

In sum, we believe the range of new theoretical directions that could extend from the logic, theorizing, and the analytical processes presented here is broad and promising. In a world where volatility and complexity create organizational risk and unique contingencies, a systematic search for

- and study of - inversions could markedly enhance leadership and organizational theories and practices. 


\section{REFERENCES}

Aiken, L. S., West, S. G., \& Reno, R. R. 1991. Multiple regression : testing and interpreting interactions. Newbury Park, Calif.: Sage Publications.

Ajzen, I. 2001. Nature and Operation of Attitudes. Annual Review of Psychology, 52(1): 27.

Ames, D. R., \& Flynn, F. J. 2007. What Breaks a Leader: The Curvilinear Relation Between Assertiveness and Leadership. Journal of Personality \& Social Psychology, 92(2): 18p.

Avolio, B. J., \& Gibbons, T. C. 1988. Transformational leaders: A life-span approach. In J. Conger, \& R. Kanungo (Eds.), Charismatic leadership: The elusive factor in organizational effectiveness: 276-308. San Francisco? , CA? us: Jossey-Bass.

Baron, R. M., \& Kenny, D. A. 1986. The moderator-mediator variable distinction in social psychological research: Conceptual, strategic, and statistical considerations. Journal of Personality and Social Psychology, 51(6): 1173-1182.

Barrick, M. R., \& Mount, M. K. 1991. The Big Five Personality Dimensions and Job Performance: A Meta-Analysis. Personnel Psychology, 44(1): 26p.

Bass, B. M., \& Bass, R. 2008. The Bass handbook of leadership : theory, research, and managerial applications (4th ed.). New York: Free Press.

Bass, B. M., \& Steidlmeier, P. 1999. Ethics, character, and authentic transformational leadership behavior. Leadership Quarterly, 10(2): 181.

Baum, J. A. C., \& McKelvey, B. 2006. Analysis of Extremes in Management Studies. In D. J. Ketchen, \& D. D. Bergh (Eds.), Research Methodology in Strategy and Management, Vol. 3: 125-199.

Baumeister, R. F., Bratslavsky, E., Finkenauer, C., \& Vohs, K. D. 2001. Bad is stronger than good. Review of General Psychology, 5(4): 323-370.

Bower, G. H. 1981. Mood and memory. American Psychologist, 36(2): 129-148.

Brief, A. P., \& Weiss, H. M. 2002. Organization Behavior: Affect in the Workplace. Annual Review of Psychology, 53(1): 279.

Chatterjee, A., \& Hambrick, D. C. 2007. It's All about Me: Narcissistic Chief Executive Officers and Their Effects on Company Strategy and Performance. Administrative Science Quarterly, 52(3): 351-386.

Costa, P. T., \& McCrae, R. R. 1992. Revised NEO Personality Inventory (NEO-PI-R) and NEO Five Factor (NEO-FFI) Inventory Professional Manual. Odessa, FL.

Daft, R. L., \& Lewin, A. Y. 1990. Can Organizational Studies Begin to Break out of the Normal Science Straitjacket? An Editorial Essay. Organization Science, 1(1): 1.

Denrell, J. 2003. Vicarious Learning, Undersampling of Failure, and the Myths of Management. Organization Science, 14(3): 227-243.

Dumdum, U. R., Lowe, K. B., \& Avolio, B. J. 2002. A meta-analysis of transformational and transactional leadership correlates of effectiveness and satisfaction: An update and extension. In B. J. Avolio, \& F. J. Yammarino (Eds.), Transformational and charismatic leadership: the road ahead: 35-66: JAI.

Dysvik, A., \& Kuvaas, B. 2008. The relationship between perceived training opportunities, work motivation and employee outcomes. International Journal of Training and Development, 12(3): 138-157.

Eden, D., \& Sulimani, R. 2002. Pygmalian training made effective: Greater mastery through augmentation of self-efficacy and means efficacy, Transformational and charismatic leadership: The road ahead: 287-308. Oxford, UK: Elsevier. 
Engle, E. M., \& Lord, R. G. 1997. Implicit Theories, Self-Schemas, and Leader-Member Exchange. Academy of Management Journal, 40(4): 988.

Epitropaki, O., \& Martin, R. 2004. Implicit Leadership Theories in Applied Settings: Factor Structure, Generalizability, and Stability Over Time. Journal of Applied Psychology, 89(2): $18 \mathrm{p}$.

Epitropaki, O., \& Martin, R. 2005. From Ideal to Real: A Longitudinal Study of the Role of Implicit Leadership Theories on Leader-Member Exchanges and Employee Outcomes. Journal of Applied Psychology, 90(4): 18p.

Erdogan, B., Liden, R. C., \& Kraimer, M. L. 2006. Justice and Leader-Member Exchange: The Moderating Role of Organizational Culture. Academy of Management Journal, 49(2): 395-406.

Fiedler, F. E. 1970. The contingency model: a theory of leadership effectiveness. In J. S. Ott (Ed.), Classic readings in organizational behavior, 1996 ed., Vol. 17: 198-209. Belmont: Wadsworth Pub. Co.

Fleming, L. 2004. Perfecting Cross-Pollination. Harvard Business Review, 82(9): 22-24.

Forgas, J. P. 1995. Mood and judgment: The affect infusion model (AIM). Psychological Bulletin, 117(1): 39 .

Forgas, J. P. 2001. Affective Influences on Judgments and Behavior in Organizations: An Information Processing Perspective. Organizational Behavior \& Human Decision Processes, 86(1): 3-34.

Foti, R. J., \& Lord, R. G. 1987. Prototypes and Scripts: The Effects of Alternative Methods of Processing Information on Rating Accuracy. Organizational Behavior \& Human Decision Processes, 39(3): 318.

Gardner, W. L., Lowe, K. B., Moss, T. W., Mahoney, K. T., \& Cogliser, C. C. 2010. Scholarly leadership of the study of leadership: A review of The Leadership Quarterly's second decade, 2000-2009. The Leadership Quarterly, 21(6): 922-958.

George, J. M. 1990. Personality, Affect, and Behavior in Groups. Journal of Applied Psychology, 75(2): 107.

George, J. M., \& Jones, G. M. 1997. Experiencing Work: Values, Attitudes, and Moods. Human Relations, 50(4): 363.

Gerstner, C. R., \& Day, D. V. 1997. Meta-Analytic Review of Leader-Member Exchange Theory: Correlates and Construct Issues. Journal of Applied Psychology, 82(6): 827.

Glynn, M. A., \& Raffaelli, R. 2010. Uncovering Mechanisms of Theory Development in an Academic Field: Lessons from Leadership Research. Academy of Management Annals, 4: 359.

Graen, G. B., \& Uhl-Bien, M. 1995. Relationship-based approach to leadership: Development of leader-member exchange (LMX) theory of leadership over 25 years: Applying a multi-level multi-domain perspective. The Leadership Quarterly, 6(2): 219-247.

Greene, W. H. 2003. Econometric analysis (5th ed.). Upper Saddle River, N.J.: Prentice Hall.

Hannah, S. T., Uhl-Bien, M., Avolio, B. J., \& Cavarretta, F. L. 2009. A framework for examining leadership in extreme contexts. The Leadership Quarterly, 20(6): 897-919.

Harquail, C. V., \& Wilcox King, A. 2010. Construing Organizational Identity: The Role of Embodied Cognition. Organization Studies (01708406), 31(12): 1619.

Harris, K. J., \& Kacmar, K. M. 2006. Too Much of a Good Thing: The Curvilinear Effect of LeaderMember Exchange on Stress. Journal of Social Psychology, 146(1): 65-84.

Hauge, L. J., Skogstad, A., \& Einarsen, S. 2007. Relationships between stressful work environments and bullying: Results of a large representative study. Work \& Stress, 21(3): 220-242. 
Hersey, P., \& Blanchard, K. H. 1969. Life cycle theory of leadership. In J. S. Ott (Ed.), Classic readings in organizational behavior, 1996 ed., Vol. 16: 189-. Belmont: Wadsworth Pub. Co.

Hiller, N. J., DeChurch, L. A., Murase, T., \& Doty, D. 2011. Searching for Outcomes of Leadership: A 25-Year Review. Journal of Management, 37(4): 1137.

Hogan, R., Hogan, J., \& Kaiser, R. 2010. Management derailment: Personality assessment and mitigation. In S. Zedeck (Ed.), APA handbook of industrial and organizational psychology, 1st ed. Washington, DC: American Psychological Association.

House, R. J. 1996. Path-goal theory of leadership: Lessons, legacy, and a reformulated theory. Leadership Quarterly, 7(3): 323.

Hu, S., Blettner, D., \& Bettis, R. A. 2011. Adaptive aspirations: performance consequences of risk preferences at extremes and alternative reference groups. Strategic Management Journal, 32(13): 1426.

Judge, T. A., Ilies, R., Bono, J. E., \& Gerhardt, M. W. 2002. Personality and Leadership: A Qualitative and Quantitative Review. Journal of Applied Psychology, 87(4): 16p.

Judge, T. A., LePine, J. A., \& Rich, B. L. 2006. Loving Yourself Abundantly: Relationship of the Narcissistic Personality to Self- and Other Perceptions of Workplace Deviance, Leadership, and Task and Contextual Performance. Journal of Applied Psychology, 91(4): 762.

Kahneman, D., \& Tversky, A. 1979. Prospect Theory: An Analysis of Decision under Risk. Econometrica, 47: 263-291.

Kalnins, A. 2007. Sample selection and theory development: implications of firms' varying abilities to appropriately select new ventures. Academy of Management Review, 32(4): 1246-1264.

Kenney, R. A., Blascovich, J., \& Shaver, P. R. 1996. Implicit Leadership Theories: Prototypes for New Leaders. Basic \& Applied Social Psychology, 15(4): 409.

Keppel, G., \& Wickens, T. D. 2004. Design and analysis: a researcher's handbook. Upper Saddle River, N.J.: Pearson Prentice Hall.

Lewicki, R. J., \& Wiethoff, C. 2000. Trust, Trust Development, and Trust Repair. In M. Deutsch, \& P. T. Coleman (Eds.), The handbook of conflict resolution : theory and practice, $1 \mathrm{st}$ ed.: 86-107. San Francisco: Jossey-Bass.

Lipman-Blumen, J. 2005. The allure of toxic leaders : why we follow destructive bosses and corrupt politicians--and how we can survive them. Oxford ; New York: Oxford University Press.

Lord, R. G., Foti, R. J., \& De Vader, C. L. 1984. A Test of Leadership Categorization Theory: Internal Structure, Information Processing, and Leadership Perceptions. Organizational Behavior \& Human Performance, 34(3): 343.

Lord, R. G., \& Maher, K. J. 1993. Leadership and information processing : linking perceptions and performance. London ; New York: Routledge.

Lowe, K. B., \& Galen Kroeck, K. 1996. Effectiveness correlates of transformational and transactional leadership: A meta-analytic. Leadership Quarterly, 7(3): 385.

March, J. G. 1991. Exploration and Exploitation in Organizational Learning. Organization Science, 2(1): 71.

Marion, R., \& Uhl-Bien, M. 2007. Introduction to the Special Issue on Leadership and Complexity. Leadership Quarterly, 18(4): 4p.

Mohr, L. B. 1982. Explaining organizational behavior (1st ed.). San Francisco: Jossey-Bass.

Piccolo, R. F., Bardes, M., Mayer, D. M., \& Judge, T. A. 2008. Does high quality leader -member exchange accentuate the effects of organizational justice? European Journal of Work and Organizational Psychology, 17(2): 273-298. 
Piccolo, R. F., \& Colquitt, J. A. 2006. Transformational Leadership and Job Behaviors: the Mediating Role of Core Job Characteristics. Academy of Management Journal, 49(2): 327.

Preacher, K. J., Curran, P. J., \& Bauer, D. J. 2006. Computational Tools for Probing Interactions in Multiple Linear Regression, Multilevel Modeling, and Latent Curve Analysis. Journal of Educational and Behavioral Statistics, 31(4): 437-448.

Rosch, E. 1978. Principle in categorization. In E. Rosch, \& B. B. Lloyd (Eds.), Cognition and categorization: viii, 328 p. Hillsdale, N.J.: L. Erlbaum Associates.

Salgado, J. 2002. The Big Five personality dimensions and counterproductive behaviors. International Journal of Selection and Assessment, 10, : 117-125.

Schoonhoven, C. B. 1981. Problems with Contingency Theory: Testing Assumptions Hidden within the Language of Contingency "Theory". Administrative Science Quarterly, 26(3): 349-377.

Schoorman, F. D., Mayer, R. C., \& Davis, J. H. 2007. An Integrative Model of Organizational Trust: Past, Present, and Future. Academy of Management Review, 32(2): 344.

Schriesheim, C. A., Castro, S. L., \& Cogliser, C. C. 1999. Leader-member exchange (LMX) research: A comprehensive review of theory, measurement, and data-analytic practices. Leadership Quarterly, 10(1): 63.

Sørensen, J. B. 2002. The Strength of Corporate Culture and the Reliability of Firm Performance. Administrative Science Quarterly, 47(1): 70.

Sorenson, O., \& Sørensen, J. B. 2001. Finding the right mix: franchising, organizational learning, and chain performance. Strategic Management Journal, 22(6/7): 713.

Sparrowe, R. T., \& Liden, R. C. 1997. Process and structure in leader-member exchange. Academy of Management Review, 22(2): 522-552.

Srull, T. K., \& Wyer, R. S. 1989. Person memory and judgment. Psychological Review, 96(1): 5883.

Starbuck, W. H. 2009. Perspective--Cognitive Reactions to Rare Events: Perceptions, Uncertainty, and Learning. Organization Science, 20(5): 925-937.

Staw, B. M., Sutton, R. I., \& Pelled, L. H. 1994. Employee Positive Emotion and Favorable Outcomes at the Workplace. Organization Science, 5(1): 51.

Taleb, N. 2007. The black swan: the impact of the highly improbable (1st ed.). New York: Random House.

Taylor, A., \& Greve, H. R. 2006. Superman or the Fantastic Four? Knowledge Recombination and Experience in Innovative Teams. Academy of Management Journal, 49(4): 723-740.

Tepper, B. J. 2007. Abusive Supervision in Work Organizations: Review, Synthesis, and Research Agenda. Journal of Management, 33(3): 261.

Uhl-Bien, M. 2006. Relational Leadership Theory: Exploring the social processes of leadership and organizing. Leadership Quarterly, 17(6): 654.

Uhl-Bien, M., \& Maslyn, J. M. 2003. Reciprocity in Manager-Subordinate Relationships: Components, Configurations, and Outcomes. Journal of Management, 29(4): 511-532.

Walumbwa, F. O., Avolio, B. J., \& Zhu, W. 2008. How Transformational Leadership Weaves Its Influence on Individual Job Performance: The Role of Identification and Efficacy Beliefs. Personnel Psychology, 61: 793-825.

Weick, K. E. 1995. Sensemaking in Organizations. Thousands Oaks, CA: Sage.

Yukl, G. A. 2010. Leadership in organizations (7th ed.). Upper Saddle River, N.J.: Prentice Hall.

Zahn, G. L., \& Wolf, G. 1981. Leadership and the Art of Cycle Maintenance: A Simulation Model of Superior--Subordinate Interaction. Organizational Behavior \& Human Performance, 28(1): 26 . 
Zajonc, R. B. 2000. Closing the debate on the primacy of affect. In J. P. Forgas (Ed.), Feeling and thinking : the role of affect in social cognition: xvi, 421 p. Cambridge: Cambridge University Press.

\section{APPENDIX A: LINKING MODERATIONS, VARIABILITY EFFECTS, AND INVERSIONS}

\section{Effects on Variability}

The main approach to theory development in organizational studies, as illustrated by Mohr (1982), has been to theorize the effect of factors on mean levels of outcome variables. However, as suggested in the seminal exploration and exploitation study (March, 1991), effects on the variability of the dependent variable (i.e., effect on the spread of the DV) matter more than effects on the mean, as variability can predict important extreme outcomes (e.g., extremely low and high performance). Considering effects on variability, and distinguishing average from extraordinary outcomes, amounts to a mean-variance tradeoff (March, 1991) as has been described in a few organizational papers—some conceptual (Denrell, 2003; Kalnins, 2007) and some empirical—with different wording used for variability ("volatility" in Chatterjee \& Hambrick, 2007; "risk" in Fleming, 2004; "reliability" in Sørensen, 2002; in Sorenson \& Sørensen, 2001; and "variance" in Taylor \& Greve, 2006).

To illustrate the idea of a mean-variance tradeoff, consider a stylized example where a leadership factor (predictor) is associated with follower performance (outcome) as measured on a 7-point scale. Consider six hypothetical cases in which scores on the performance variable are 2, 3 and 4 when the leadership factor is "low," and 1,4 and 7 when the leadership factor is "high" (for simplicity purposes we assume one observes only $2 \times 3$ outcomes, with values scaled arbitrarily). In this example, if interested in average effects one could build and verify a theory stating that "the leadership predictor has a beneficial effect" since the expected value moves from an average of 3 to 
4 when the predictor increases. Paradoxically, one could just as well build and verify a theory that "the factor has a detrimental effect beyond a given threshold" since high scores on the predictor increases the odds that an extremely low outcome could occur (i.e., a 1 or a 2).

\section{Moderations as Reflective of Variability Effects}

The previous example focused on bivariate relationships. Extending that logic, it is important to note that effects on variability are implicit in contingent or moderated relationships. That is, moderation could be formally interpreted as an effect on variability. Moderation occurs when the relationship between $\mathrm{X}$ and $\mathrm{Y}$ is dependent on a third variable, $\mathrm{M}$, which amplifies or dampens the X-Y relationship (Keppel \& Wickens, 2004). A major empirical approach for studying moderation is to estimate the effects of cross terms in regression, and to plot the regression lines for different values of the moderator, typically for values of plus and minus one standard deviation (see Figure 1.a for a typical diagram of a positive moderation).

------ Insert Figure 1 here -----

However, moderation can be interpreted as a straightforward effect of the factors on the variability of the dependent variable. To illustrate, Figure 1.b plots the distribution of Y for different values of $\mathrm{X}$ assuming the moderator and dependent variable to be normally distributed. The change in variability in the outcome based on various values of the moderator is directly implied by the fanlike pattern shown in the moderation lines. The graph lines reflecting two values of the moderators can now be viewed as quantile lines (i.e., lines linking points of equal probability) and one can start imagining other quantile lines that may be present for values of the moderator further from its mean, creating even greater variance in the outcome construct (Figure 1.c). In sum, the difference in slopes for different values of the moderator form a fan-like pattern reflecting the effect on the variability of the dependent variable and, in some cases, may invert the X-Y relationship at a certain threshold value of $\mathrm{M}$. 
This reasoning has relied so far only on the ideas that the moderation being considered is reflected by two non-crossing regression lines, and that the moderator has effects on the outcome beyond two discrete values, normally plus and minus one standard deviation. When seeing two noncrossing moderating lines (Figure 1.a), we recommend that one attempt to visualize the effect on the variability (Figure 1.b) and mentally extends the pattern, assuming the moderator were to take a larger range, which would at a critical point change in slope from positive to negative (or vice versa) (Figure 1.c). By contrast, simple effects on variability are more difficult to visualize in a crossover interaction, when the two moderation lines cross as illustrated in Figure 1.d as this cannot be easily interpreted as a simple effect of the moderator on the variability of $Y$. In this paper, because we are interested in countervailing effects suggested by first order effects on variability, we only consider moderation effects that are non-crossing. Also, to be clear, we focus on linear interactions, i.e., only discussing straight regression lines, some with positive slopes and some with negative slopes as influenced by the moderator, and do not deal with nuanced issues of curvilinearity.

\section{APPENDIX B : STEPS TO COMPUTE THE INVERSION LEVEL}

This appendix outlines the analytical steps contained in our new method applied to the 29 studies for which all necessary details were available.

\section{Step 1: Gathering Information about Variability Effects from a Moderation Analysis}

We consider that any moderation graph can be interpreted as providing not only first moment (mean) but also second moment (variability) effects (Baron \& Kenny, 1986). Figure 2 shows howfor two points (Low and High) of the independent variables (IV) — to read approximate values and the relationship to the dependent variable (DV) at plus $(+1 \mathrm{std})$ and minus $(-1 \mathrm{std})$ one standard deviation. 
Through Equation 1, researchers can exploit this information to compute the mean $(\mu)$ and the standard deviation $(\sigma)$ of the distribution of the DV for two arbitrary points (Low and High) of the IV (Greene, 2003):

Equation 1: $\mu_{H}=\frac{Y_{H-}+Y_{H+}}{2} \quad \mu_{L}=\frac{Y_{L-}+Y_{L+}}{2} \quad \sigma_{H}=\frac{Y_{H-}-Y_{H+}}{2} \quad \sigma_{L}=\frac{Y_{L-}-Y_{L+}}{2}$

\section{Step 2: Computing the Critical Level}

To compute at what point an inversion might occur, we determine at which level the quantile lines change slope (from positive to negative or vice versa). We label this level "critical level" because the slope changes direction there, and we subscript $\mathrm{c}$ all variables (performance $\mathrm{Y}$, moderator $\mathrm{M}$, etc.) related to that juncture:

$$
\text { Equation 2: } Y_{c}=\left(\frac{\mu_{H}}{\sigma_{H}}-\frac{\mu_{L}}{\sigma_{L}}\right) /\left(\frac{1}{\sigma_{H}}-\frac{1}{\sigma_{L}}\right)
$$

\section{Step 3: Putting it All Together}

The information about the distribution of the DV from Equation 1 is entered into Equation 2 to compute the critical level of the dependent variable $(\mathrm{Yc})$, which can be transformed into a $\mathrm{z}$-score $\left(z_{c}\right)$. Finally, that $z$-score can be applied to the moderator distribution to estimate at which critical value of the moderator $\left(M_{c}\right)$ the quantile line changes direction, identifying the point at which the slope of the relationship between the IV and DV inverts.

\section{Step 4: Selecting for Final Sample}

We performed checks to eliminate studies in which the critical value of the moderator where the inversion occurred was outside its measured range (e.g., we excluded studies where the inversion occurs at a value below 1 or above 4 if the moderator has a scale of 1 to 4). Similarly, we focused only on studies where the inversion occurs at a value of the dependent variable $(Y)$ that was within its possible measurement range. Our inductive approach thus probes for under-theorized inversion 
phenomena that can occur in the tails of distributions yet within reasonable ranges of the factors, an approach consistent with literature on ordinal vs. disordinal interactions (Aiken et al., 1991:23).

Our analysis was expected to retain only a minority of studies, given that such inversions - if potentially theoretically important - would nevertheless be somewhat rare. The computation and selection on the 29 exploitable studies produced a sample of five studies signaling that an inversion might occur (see summary information in Table 1 and extract of the graphs in Table 2). 


\section{TABLE 1}

\section{Summary of Selected Studies}

\begin{tabular}{|c|c|c|c|c|c|}
\hline Study & $\begin{array}{l}\text { Generally Accepted } \\
\text { Mean Theory }\end{array}$ & Moderator & $\begin{array}{l}\text { Empirical } \\
\text { Plausibility }\end{array}$ & New Theory & Potential Mechanism \\
\hline $\begin{array}{l}\text { (Piccolo \& } \\
\text { Colquitt, } \\
\text { 2006 Fig. 3a) }\end{array}$ & $\begin{array}{l}\text { Transformational } \\
\text { leadership has a positive } \\
\text { effect on core job } \\
\text { characteristics } \\
\text { perceptions. }\end{array}$ & LMX & $\begin{array}{l}M_{c}=1.9[1-5] \\
Q_{c}=4 \%\end{array}$ & $\begin{array}{l}\text { In very low values of LMX, } \\
\text { transformational leadership could } \\
\text { have a negative impact on core job } \\
\text { characteristics perception. }\end{array}$ & $\begin{array}{l}\text { Change of nature of construct: at low values of } \\
\text { LMX, leader does not lack prototypical qualities } \\
\text { of LMX, but is perceived as having negative } \\
\text { (anti-prototypical qualities), leading to negative } \\
\text { affect infusion. }\end{array}$ \\
\hline $\begin{array}{l}\text { (Piccolo et } \\
\text { al., } 2008 \text { Fig. } \\
1 \& 3)\end{array}$ & $\begin{array}{l}\text { Procedural justice has a } \\
\text { positive effect on felt } \\
\text { obligation. }\end{array}$ & LMX & $\begin{array}{l}M_{c}=2.73[1-5] \\
Q_{c}=17 \%\end{array}$ & $\begin{array}{l}\text { In very low values of LMX, } \\
\text { procedural justice could have a } \\
\text { negative impact on felt obligation. }\end{array}$ & $\begin{array}{l}\text { Change of nature of construct: at low values of } \\
\text { LMX, leader does not lack prototypical qualities } \\
\text { of LMX, but is perceived as having negative } \\
\text { (anti-prototypical qualities), leading to negative } \\
\text { affect infusion. }\end{array}$ \\
\hline $\begin{array}{l}\text { (Erdogan et } \\
\text { al., } 2006 \text { Fig. } \\
\text { 3a\&3b) }\end{array}$ & $\begin{array}{l}\text { Interactional justice and } \\
\text { distributive justice have } \\
\text { positive impacts on } \\
\text { LMX. }\end{array}$ & $\begin{array}{l}\text { Team } \\
\text { orientation }\end{array}$ & $\begin{array}{l}M_{c}=6.63[1-7] \\
Q_{c}=99.8 \% \\
\text { (with IV }= \\
\text { Distributive Justice: } \\
M_{c}=6.33[1-7] \\
Q_{c}=98.9 \% \text { ) }\end{array}$ & $\begin{array}{l}\text { In very high values of team } \\
\text { orientation, perceived justice (IJ \& } \\
\text { DJ) would have a negative impact on } \\
\text { LMX. }\end{array}$ & $\begin{array}{l}\text { Inter-construct interaction: at high values of } \\
\text { team orientation, justice constructs are } \\
\text { perceived through a transactional lens, so } \\
\text { negatively. } \\
\text { Shift through levels: at high values of team } \\
\text { orientation, a communal perspective eschews a } \\
\text { dyadic perspective of leadership. }\end{array}$ \\
\hline $\begin{array}{l}\text { (Walumbwa } \\
\text { et al., } 2008 \\
\text { Fig. } 2 \mathrm{a} \text { ) }\end{array}$ & $\begin{array}{l}\text { Identification with work } \\
\text { unit has a positive effect } \\
\text { on individual } \\
\text { performance. }\end{array}$ & $\begin{array}{l}\text { Means } \\
\text { efficacy }\end{array}$ & $\begin{array}{l}M_{c}=2.58[1-5] \\
Q_{c}=4 \%\end{array}$ & $\begin{array}{l}\text { In very low values of means efficacy, } \\
\text { identification with work unit could } \\
\text { have a negative impact on individual } \\
\text { performance. }\end{array}$ & $\begin{array}{l}\text { Shift through Levels: low values of means } \\
\text { efficacy imply low group efficacy, which } \\
\text { contradicts work unit identification. }\end{array}$ \\
\hline $\begin{array}{l}\text { (Dysvik \& } \\
\text { Kuvaas, } 2008 \\
\text { Fig. 1) }\end{array}$ & $\begin{array}{l}\text { Perceived training } \\
\text { opportunities have } \\
\text { positive effects on OCB. }\end{array}$ & $\begin{array}{l}\text { Intrinsic } \\
\text { motivation }\end{array}$ & $\begin{array}{l}M_{c}=3.75[1-5] \\
Q_{c}=46 \%\end{array}$ & $\begin{array}{l}\text { In very low values of intrinsic } \\
\text { motivation, perceived training } \\
\text { opportunities have negative effects } \\
\text { on OCB. }\end{array}$ & $\begin{array}{l}\text { Change of nature of construct: when faced with } \\
\text { training opportunities, those with low intrinsic } \\
\text { motivation reframe the opportunity instead as a } \\
\text { threat. }\end{array}$ \\
\hline
\end{tabular}

Note a: $M_{0} Q_{i}$ : these are the "critical" values of the Moderator and the Quantile at which the inversion is suspected to occur. For the moderator, we indicate between brackets the range of the measure. So $M_{c}=1.9$ [1-5] indicates an inversion for a value 1.9 in a range from 1 to 5 . The quantile indicates position in the tail of the distribution, so $Q_{c}=4 \%$ indicates that inversion would occur for the bottom $4 \%$ of the values of the moderator in that sample; $Q_{c}=98.9 \%$ indicate inversion to occur for the top $1.1 \%$ of the values of the moderator.

Note b: By default, the numerical values derive from using the method of this paper, based on moderation graph; when the regression table was available, we however reported results based on reported coefficient (Schoonhoven, 1981:377, appendix A). In these cases (Dysvik \& Kuvaas, 2008; Hauge, Skogstad, \& Einarsen, 2007; Piccolo et al., 2008; Walumbwa et al., 2008), the results between both approaches did not differ substantially. 
TABLE 2

\section{Excerpts from Selected Studies}

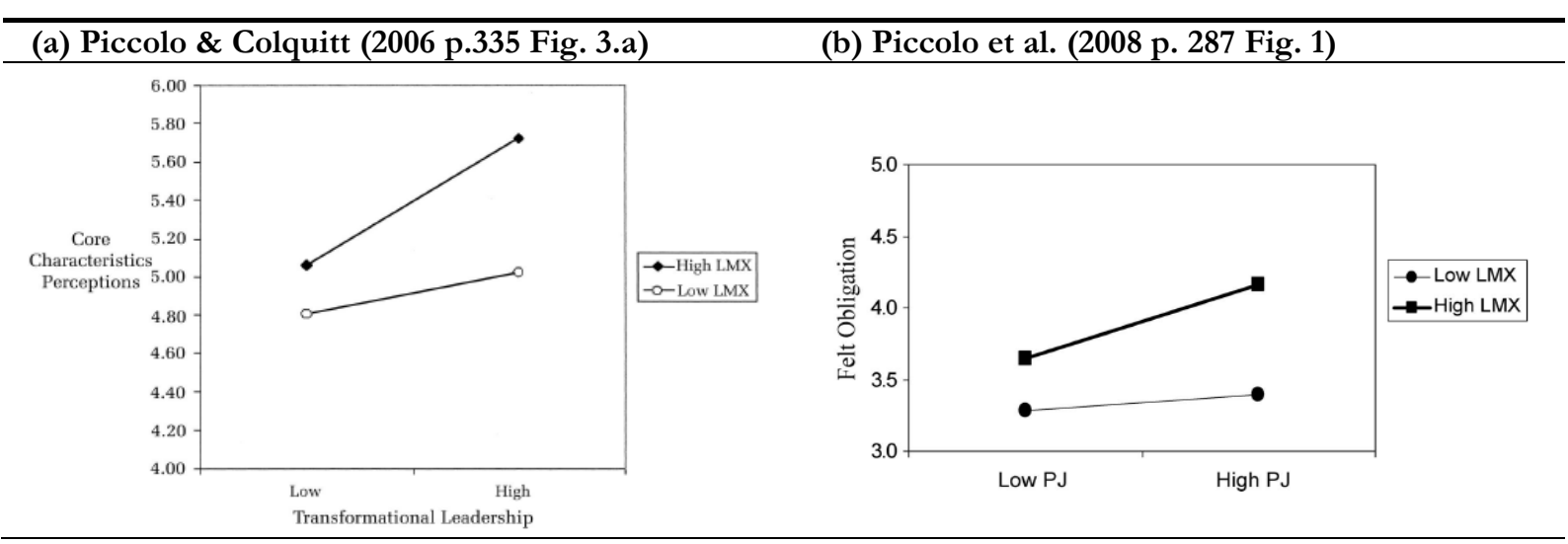

(c) Erdogan et al. (2006 p.402 Fig. 3a)

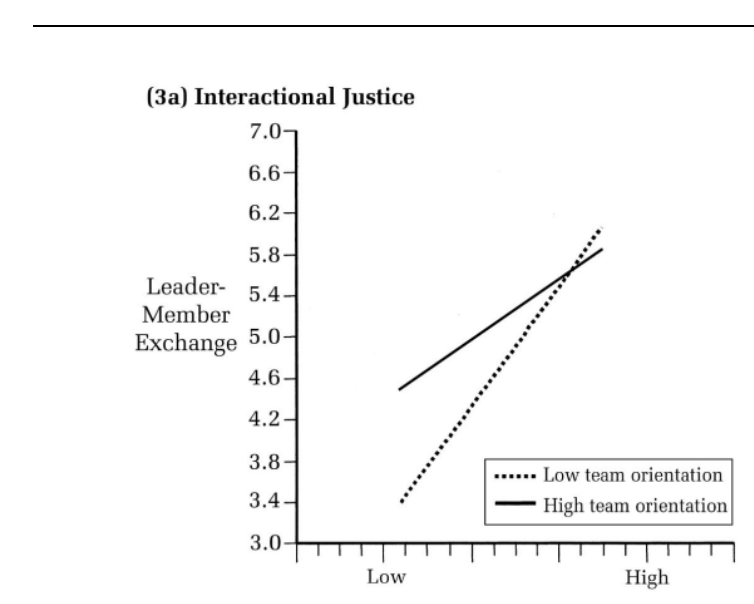

(d) Walumbwa et.al. (2008 p.813 Fig. 2a)

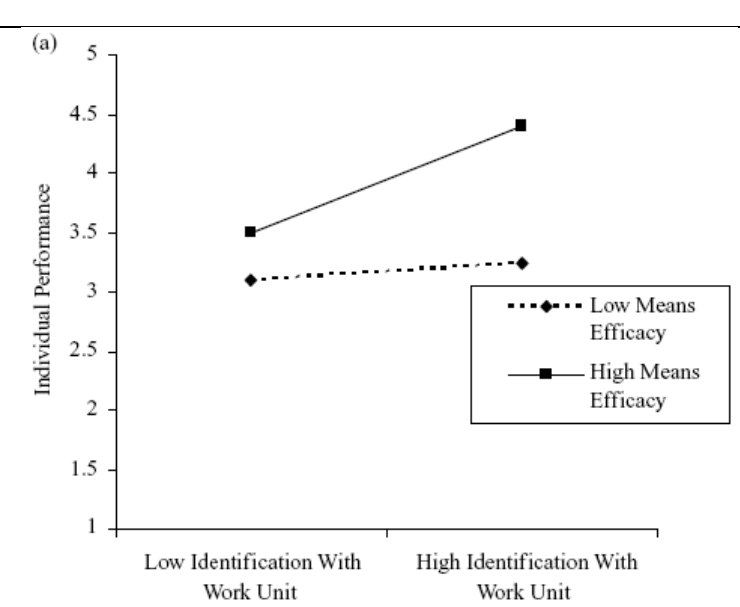

(e) Dysvik \& Kuvaas (2008 Fig. 1)

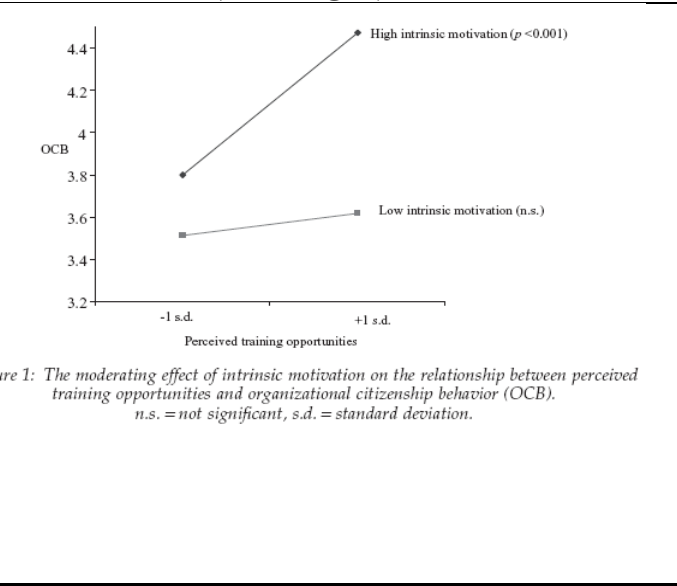




\section{FIGURE 1}

\section{Moderations, Implied Variability Effects and Inversion of Effects}

(a) Theory with moderation (suggests an increase in variability)

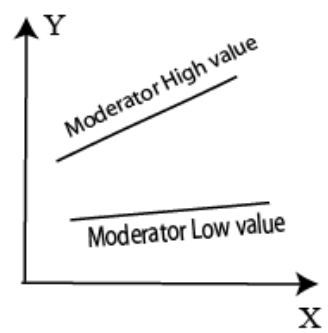

(c) Same theory, plotting quantile regressions for extra-ordinary values of the moderator

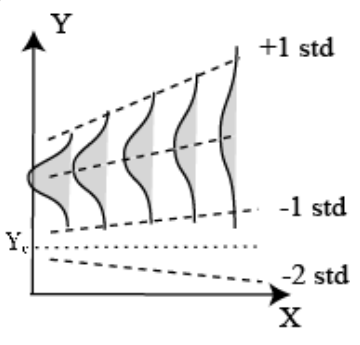

(b) Same theory, assuming moderator and dependent variables are random normal variables

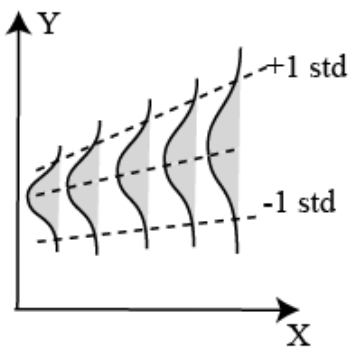

(d) Case with crossover moderation (variability effect is not straightforward)

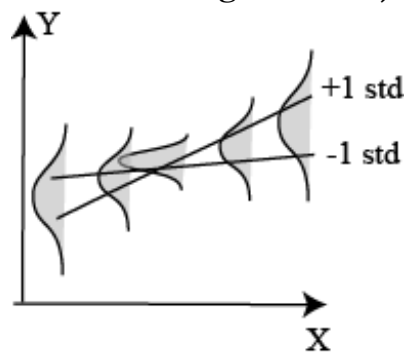

Note: in the above diagrams, the sketched distributions (Gaussian curves) represent the distribution of the dependent variable $(\mathrm{Y})$. The successive distribution sketches are signaling that the variability of the dependent variable $(\mathrm{Y})$ is being influenced by the value of the independent variable $(\mathrm{X})$

FIGURE 2

\section{Collecting Distributional Information from a Moderation Graph}

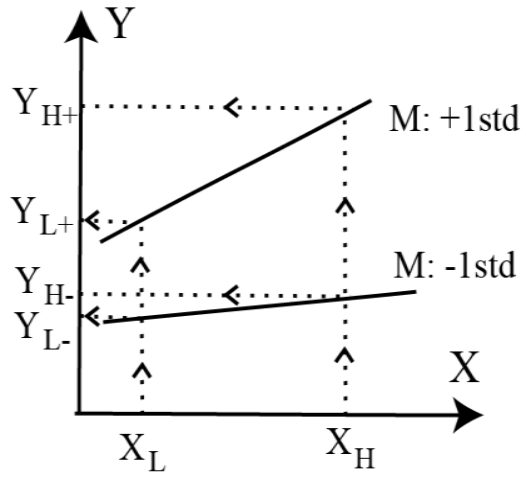




\section{ESSEC Business School}

Avenue Bernard Hirsch

CS 50105 Cergy

95021 Cergy-Pontoise Cedex

France

Tél. + 33 (0)134433000

Fax +33 (0)134433001

www.essec.fr

ESSEC Executive Education

CNIT BP 230

92053 Paris-La Défense

France

Têl. + $33(0) 146924900$

Fax +33(0)1 46924990

www.executive-education.essec.fr

\section{Contact:}

Research Center

ESSEC Asia-Pacific

100 Victoria Street

National Library \# 13-02

Singapore 188064

Têl. +65 68849780

Fax +6568849781

www.essec.edu/asia 